\title{
Cell Type-Dependent Divergence of Transactivation by Glucocorticoid Receptor Ligand
}

\author{
Kiyoshi Tanigawa, ${ }^{*}$ Katsunao Tanaka, Hideki Nagase, Hidekazu Miyake, Mamoru Kiniwa, and \\ Koichi IKIZAWA \\ Pharmacobioregulation Research Laboratory, Taiho Pharmaceutical Co., Ltd.; 1-27 Misugidai, Hanno, Saitama \\ 357-8527, Japan. Received July 3, 2002; accepted September 11, 2002; published online September 12, 2002
}

\begin{abstract}
The glucocorticoid receptor regulates gene expression mainly by two mechanisms; transactivation and transrepression. A ligand with strong transrepression and weak transactivation activity is predicted to be a beneficial agent with potent anti-inflammatory activity and minor adverse effects. Recently, the profile of a synthetic steroid, RU24858, has been reported to fulfill this condition in vitro, but others have reported no dissociation between the anti-inflammatory activity and side effects in vivo. To gain further information on the profile of this compound, we evaluated its transactivation ability using a reporter gene analysis both in vitro and in vivo. In the in vitro analysis, RU24858 demonstrated only a weak transactivation activity in HeLa cells, when compared with prednisolone. In CV-1 cells, however, these two glucocorticoids exhibited equivalent transactivation activities. This behavior is independent of whether the reporter gene is regulated by mouse mammary tumor virus promoter or multiple copies of glucocorticoid response element. When the reporter plasmid was inoculated into mouse abdominal skin using a gene gun, followed by orally administration of glucocorticoids, RU24858 induced significantly higher reporter enzyme activity than prednisolone. These results suggest that the profile of RU24858 is divergent and its transactivation ability is comparable to prednisolone depending on the cell-type both in vitro and in vivo.
\end{abstract}

Key words glucocorticoid receptor; dissociated ligand; transactivation

Glucocorticoids regulate numerous physiological processes such as regulation of endocrine and metabolic processes as well as modulation of stress and immunological responses. ${ }^{1)}$ Therefore, a wide range of adverse effects accompanies the beneficial anti-inflammatory effect of glucocorticoid treatment. ${ }^{2,3)}$ Progressive understanding of the molecular mechanism of the glucocorticoid receptor (GR) action in the recent years has highlighted a new approach towards the development of a ligand with reduced side effects. The GR regulates gene transcription by two modes, namely, transactivation and transrepression. ${ }^{4-12)}$ Transactivation occurs when the GR binds to $c i s$-acting glucocorticoid response element (GRE) and acts as a transcription factor to induce the expression of target genes. Transrepression is mediated via protein-protein interactions with other transcription factors such as AP-1 and $\mathrm{NF}-\kappa \mathrm{b}$, thereby suppressing the transcriptional activities of these factors. Transrepression is believed to be the basis of anti-inflammatory effects, whereas transactivation is assumed to cause side effects. ${ }^{13-15)}$ Therefore, the dissociation of these two mechanisms would possibly lead to a therapeutically safer steroid. ${ }^{3,16)}$

A novel class of synthetic glucocorticoid, RU24858, has recently been identified that exerts strong transrepression activity and only weak transactivation activity in vitro. ${ }^{17)}$ In addition, this compound exhibits anti-inflammatory activity in vivo. A subsequent study, however, demonstrated that RU24858 induces systemic changes, including thymus involution and body weight loss, with similar potency to the standard glucocorticoid, budesonide. ${ }^{18)}$ This raised doubt on the validity to separate transrepression from transactivation, but whether the dissociated profile of RU24858 remains intact even in vivo is still uncertain. In general, the in vitro profile of a compound does not necessarily translate to the in vivo profile because of the metabolic conversion. In this study, we refined the transactivation activity of RU24858 not only in in vitro but also in in vivo systems. Our results suggest that the dissociated profile of this compound is not a rigid one.

\section{MATERIALS AND METHODS}

Cells and Chemicals HeLa cells and CV-1 were purchased from Dainippon Pharm. (Osaka, Japan) and were maintained at $37{ }^{\circ} \mathrm{C}$ in a humidified atmosphere with $5 \%$ $\mathrm{CO}_{2}$ in Eagle's minimum essential medium (MEM) supplemented with $10 \%$ charcoal-treated fetal calf serum (FCS), $100 \mathrm{U} / \mathrm{ml}$ penicillin and $100 \mu \mathrm{g} / \mathrm{ml}$ streptomycin. H4-II-E cells (Dainippon Pharm.) were cultured under the same conditions, but with $5 \%$ charcoal-treated FCS. Dexamethasone (DEX) and prednisolone (PRED) were purchased from Nacalai Tesque Inc. (Kyoto, Japan). RU24858 was synthesized by Taiho Pharmaceutical Co., Ltd. (Saitama, Japan). The structure and purity of RU24858 was confirmed by HPLC, FAB-MS, ${ }^{1} \mathrm{H}-\mathrm{NMR}$ spectra, and elementary analysis.

Plasmids pMAMneoLUC, containing mouse mammary tumor virus (MMTV) promoter, and pGRELUC, containing three copies of GRE, were purchased from Clontech Laboratories (Palo Alto, CA, U.S.A.). To construct the human GR expression vector (pBK-hGR), human GR cDNA was amplified from pRShGR (American Type Culture Collection, Rockville: ATCC, MD) by polymerase chain reaction (PCR) with the following two primers; sense 5'-CGCCATGGATGGATCCACCATGGACTCCAAAGAATC- ${ }^{\prime}$ and antisense 5'-GCTCTAGATCACTTTTGATGAAACAGAAGT-3' . $B a m \mathrm{HI}$ and $X b a \mathrm{I}$ restriction sites were introduced into sense and antisense primers, respectively. The amplified products were digested with $B a m \mathrm{HI}$ and $X b a \mathrm{I}$, and ligated into compatible sites of pBK-CMV (Stratagene, La Jolla, CA, U.S.A.). The NheI-SpeI fragment of the resultant construct, corresponding to lac promoter and LacZ ATG, was removed to increase the expression level. The human GR expression 
vector was verified by DNA sequencing.

Reporter Gene Assay The cells were seeded in 24-well plates such that they were subconfluent at the time of the experiment. For the reporter gene assay, the cells in each well were transiently transfected with the indicated amounts of pBK-hGR $(0.1 \mu \mathrm{g})$ and either pMAMneoLUC or pGRELUC $(0.3 \mu \mathrm{g})$. After $6 \mathrm{~h}$, the transfection mixture was replaced with MEM supplemented with $10 \%$ FCS and then the cells were treated with GCs for $16 \mathrm{~h}$. The transfected cells were lysed with $100 \mu \mathrm{l}$ of cell culture lysis reagent (Promega Corp., Madison, WI). After centrifugation at $10000 \times \boldsymbol{g}$ for $5 \mathrm{~min}, 20 \mu \mathrm{l}$ of supernatant was added to $100 \mu \mathrm{l}$ of luciferase assay reagent (Promega) and counted with a luminescencer AB-2000 (Atto, Tokyo, Japan).

Tyrosine Aminotransferase (TAT) Assay H4-II-E cells were cultured in 24-well plates to confluency, and then treated with GCs for $16 \mathrm{~h}$. TAT activity was assayed using the method of Granner and Tomkins. ${ }^{19)}$

Mice Male ICR mice, 5 weeks old, weighing 25-33 g were obtained from CLEA Japan (Shizuoka, Japan). The animals were maintained under a 12-h light/dark cycle in a temperature- and humidity-controlled room.

Evaluation of Transactivation Activity in Vivo Transfection particles were made as described previously. ${ }^{20)}$ Briefly, $50 \mu \mathrm{g}$ of pMAMneoLUC and $50 \mu \mathrm{g}$ of pBK-hGR were mixed and precipitated onto $50 \mathrm{mg}$ of $1 \mu \mathrm{m}$ gold particles. The particles were suspended in ethanol containing $0.05 \mathrm{mg} / \mathrm{ml}$ polyvinyl pyrrolidone and coated onto the inner surface of tubing, which resulted in a delivery of $1 \mu \mathrm{g}$ DNA/0.5 mg gold per shot. Gene gun inoculations were delivered to depilated abdominal skin of mice using the Helios gene gun at a helium discharge pressure of 200 pounds per square inch. The next morning, glucocorticoids were orally administrated to the mice. After $6 \mathrm{~h}$, the skin, which was bombarded, was excised from the transfected region, soaked in $500 \mu \mathrm{l}$ of cell culture lysis reagent (Promega), and homogenized using a Mixer Mill MM300 (Retsch, Germany). After centrifugation at $10000 \times \boldsymbol{g}$ for $5 \mathrm{~min}, 20 \mu \mathrm{l}$ of supernatant was assayed for the luciferase activity.

Statistical Analysis The statistical differences between groups were analyzed by the Welch's $t$-test and Dunnett's multiple range test. A $p$ value of less than 0.05 was considered to be significant.

\section{RESULTS}

In Vitro Transactivation Activity of RU24858 To thoroughly investigate the in vitro transactivation activity of RU24858, a reporter gene analysis was performed in HeLa and CV-1 cells transiently transfected with either MMTVbased or GRE-based reporter plasmid. In HeLa cells expressing endogenous GR, RU24858 scarcely stimulated the transcription of MMTV-based reporter even at $1 \mu \mathrm{M}$, whereas it induced almost the maximum response through the GRE-based reporter (Figs. 1A, B). In both cases, DEX and PRED showed remarkably strong responses compared with RU24858. CV-1 cells, lacking endogenous GR, were cotransfected with GR expression plasmid and reporter plasmid. Differently from the observation in HeLa cells, the activity of RU24858 in CV-1 cells was comparable to that of PRED, irrespective of either MMTV- or GRE-based reporter
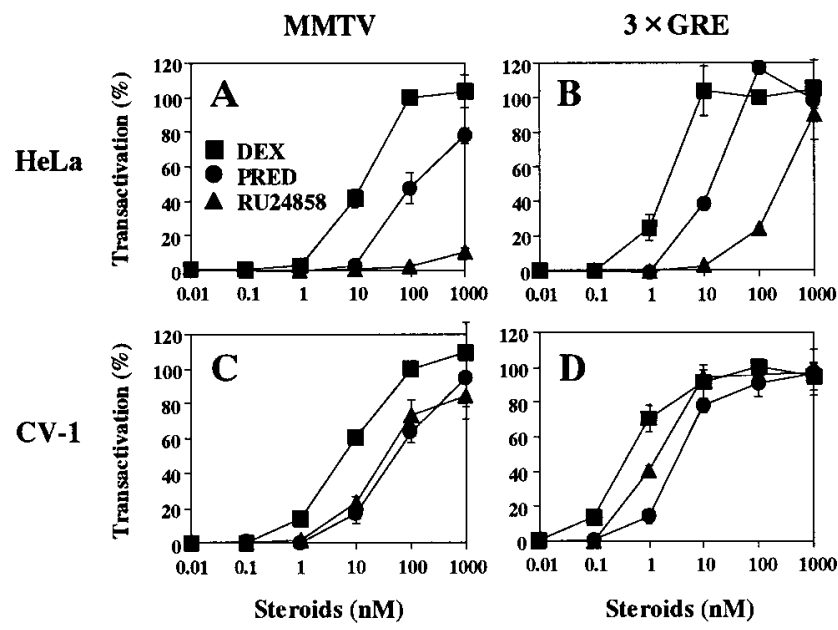

Fig. 1. Divergent Transactivation Activity of RU24858 in the Reporter Gene Assay

HeLa cells were transiently transfected with either pMAMneoLUC (A) or pGRELUC (B). CV-1 cells were transiently co-transfected with pBKhGR and either pMAMneoLUC (C) or pGRELUC (D). The transfected cells were treated with the various glucocorticoids as indicated, and assayed for luciferase activity. The results are expressed as the percentage of activation relative to the maximal response obtained with $100 \mathrm{~nm}$ of DEX. The results are presented as the mean \pm S.D. $(n=4)$.

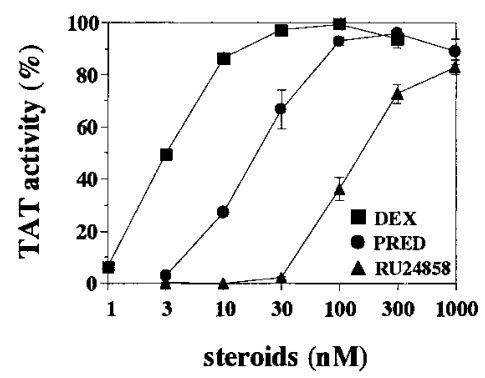

Fig. 2. TAT-Induction Activity of RU24858 in Rat Hepatoma H4-II-E Cells

H4-II-E cells were treated with the various glucocorticoids as indicated, and TAT activity in the cell lysate was measured. The results are expressed as the percentage of increase relative to the maximal response measured in cells treated with $100 \mathrm{~nm}$ of DEX. The results are presented as the mean \pm S.E. $(n=6)$.

\section{(Figs. 1C, D).}

Transactivation of an endogenous gene was next evaluated by the induction of tyrosine aminotransferase (TAT), whose expression is regulated by the GREs in its promoter. Treatment of rat hepatoma H4-II-E cells with any of DEX, PRED, or RU24858 induced enzyme activity of TAT in a dose-dependent manner (Fig. 2). In this experiment, the activity of RU24858 was slightly weak compared with PRED.

In Vivo Transactivation Potential of RU24858 To examine the transactivation activity in vivo, we introduced the MMTV-based reporter plasmid together with the GR expression plasmid into mouse abdominal skin using a gene gun. This technique enables the highly local transfer of DNAcoated gold beads into the cells. ${ }^{21-22)}$ Following the DNA transfer, the mice were orally given glucocorticoids. After $6 \mathrm{~h}$, the skin of the transfected region was dissected and assayed for the enzyme activity. PRED at $10 \mathrm{mg} / \mathrm{kg}$ induced substantial luciferase activity, which peaked after about $6 \mathrm{~h}$ of the administration (Fig. 3). ${ }^{20)}$ Likewise, RU24858 induced the enzyme activity in a dose-dependent manner (Fig. 3). The 


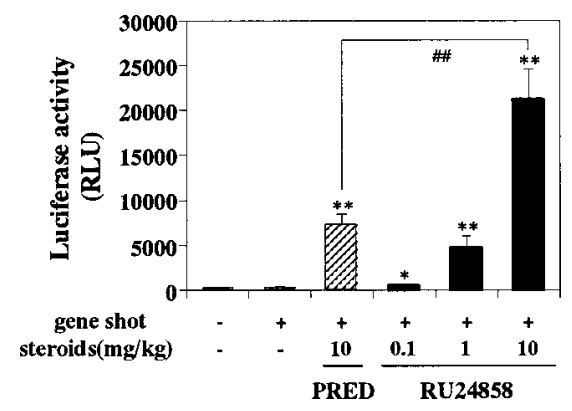

Fig. 3. In Vivo MMTV Transactivation Activity of RU24858

RU24858 and PRED were orally administrated to reporter gene-introduced mice. After $6 \mathrm{~h}$, mice skin was excised, and assayed for luciferase activity. The data are expressed as mean \pm S.E. of eight animals. ${ }^{\#} p<0.01$ for the significant differences between PRED $(10 \mathrm{mg} / \mathrm{kg})$ treatment group and RU24858 $(10 \mathrm{mg} / \mathrm{kg})$ treatment group (Welch's $t$-test). ${ }^{*} p<0.01$ and ${ }^{* *} p<0.001$ for the significant differences between vehicle group and each treatment group (Dunnett's multiple range test).

activity induced by RU24858 $10 \mathrm{mg} / \mathrm{kg}$ was significantly higher than that by PRED at the same dose. With regard to the physiological relevance of these induction levels, it should be noted that PRED at $10 \mathrm{mg} / \mathrm{kg}$ induced substantial decrease in the thymus weight as well as the serum corticosterone levels after subcutaneous administration to mice for $7 \mathrm{~d}^{20)}$

\section{DISCUSSION}

Dissociated ligands lacking transactivation function are assumed to be promising anti-inflammatory agents with reduced side effects. ${ }^{3,18,23)}$ RU24858 has been reported as such a compound that had strong transrepression and only weak transactivation functions in vitro. ${ }^{17)}$ In contrast, Belvisi et $a l .^{18)}$ reported that this compound showed systemic side effects comparable to budesonide in vivo and the predicted dissociation between anti-inflammatory activity and adverse effects could not be confirmed. It is not certain, however, whether these results indicate limitations of the concept of dissociated ligand as a beneficial agent or merely reflect limitations of RU24858 as a tool for validation. The results in the present study argue for the latter possibility, because they demonstrated that the in vitro transactivation activity of RU24858 is divergent and that this compound has a potential for transactivation even in vivo.

Transactivation activity induced by RU24858 was dependent not only on the promoter/enhancer but also on the cell type. In HeLa cells, MMTV promoter/enhancer scarcely mediated the transactivation activity of RU24858, whereas three tandem copies of GRE enhancer, fused to the minimum thymidine kinase promoter, permitted a substantial transactivation activity. This difference may be due to a heightened capability of the latter system to mediate transactivation because even DEX and PRED displayed a left shift in their dose-response curves. Vayssiere et al. ${ }^{17)}$ reported that, in HeLa cells, a minor transactivation activity of RU24858 was confirmed by $5 \times$ GRE-based reporter gene, which is slightly different from our results. This may be due to the presence of additional plasmid in their protocol or due to the number of copies of GRE. In CV-1 cells, the transactivation activity of RU24858 was remarkable compared with that in HeLa cells and equivalent to PRED. Note that the dose dependence of PRED as well as DEX is almost equal between HeLa and
CV-1 cells. Therefore, it is likely that some component, which is present in HeLa cells but not in CV-1 cells or vice versa, influences the action of RU24858. Similarly divergent action has been displayed by another synthetic steroid, RU24782, which exhibits a similar transactivation activity to DEX in mouse fibroblasts, but only a minor activity in HeLa cells. ${ }^{17}$

In the TAT induction experiment, which is supposed to be a more physiological indication of transactivation than the reporter gene system, RU24858 clearly induced the enzyme activity in rat hepatoma H4-II-E cells. Although its potency is considerably weak compared with DEX and PRED, RU24858 at $1 \mu \mathrm{m}$ induced almost the maximal response. This is in contrast to the data by Vayssiere et al. ${ }^{17)}$ demonstrating that TAT activity induced by RU24858 at $1 \mu \mathrm{M}$ is only $11 \%$ of the maximal response in mouse hepatoma HTC cells. It is difficult to discuss the reason for this discrepancy because the absolute enzyme activity expressed in each cell line might be different. It is possible that, because hepatocytes are rich in the enzymes for steroid metabolisms, the ability for metabolic conversion of RU24858 might be different between these cell lines. Likewise, in vivo potency of the compound might be modulated by metabolisms and does not necessarily correlate with in vitro data. To examine this issue, we performed an in vivo reporter gene assay and found that RU24858 showed a stronger transactivation activity than PRED. Because there is no report so far on the in vivo metabolism and stability of RU24858, it is not certain whether such an in vivo activity is ascribed to RU24858 itself or some metabolites derived from it. In any case, our results suggest that the in vivo administration of RU24858 does not realize a dissociated function.

In conclusion, our results indicate that RU24858 is not necessarily a dissociated ligand and thus is an immature tool to assess the relationship between transactivation function and adverse effects of glucocorticoids. Nevertheless, the cell type-dependent transactivation activity is unique to RU24858. The elucidation of this mechanism would be a clue to the development of selective ligands.

\section{REFERENCES}

1) Funder J. W., J. Steroid Biochem. Mol. Biol., 43, 389-394 (1992).

2) Boumpas D. T., Chrousos G. P., Wilder R. L., Cupps T. R., Balow J. E., Ann. Intern. Med., 119, 1198-1208 (1993).

3) Barnes P. J., Clin. Sci. (Colch.), 94, 557-572 (1998).

4) Evans R. M., Recent Prog. Horm. Res., 45, 1-22 (1989).

5) Diamond M. I., Miner J. N., Yoshinaga S. K., Yamamoto K. R., Science, 249, 1266-1272 (1990).

6) Jonat C., Rahmsdorf H. J., Park K. K., Cato A. C., Gebel S., Ponta H., Herrlich P., Cell, 62, 1189-1204 (1990).

7) Schule R., Rangarajan P., Kliewer S., Ransone L. J., Bolado J., Yang N., Verma I. M., Evans R. M., Cell, 62, 1217-1226 (1990).

8) Yang-Yen H. F., Chambard J. C., Sun Y. L., Smeal T., Schmidt T. J., Drouin J., Karin M., Cell, 62, 1205-1215 (1990).

9) Konig H., Ponta H., Rahmsdorf H. J., Herrlich P., EMBO J., 11, $2241-2246$ (1992).

10) McEwan I. J., Wright A. P., Gustafsson J. A., Bioessays, 19, 153-160 (1997).

11) Eggert M., Schulz M., Neeck G., J. Steroid Biochem. Mol. Biol., 77, 185-191 (2001).

12) Herrlich P., Oncogene, 20, 2465-2475 (2001).

13) Reichardt H. M., Kaestner K. H., Tuckermann J., Kretz O., Wessely O., Bock R., Gass P., Schmid W., Herrlich P., Angel P., Schutz G., Cell, 93, 531-541 (1998). 
14) Reichardt H. M., Tuckermann J. P., Gottlicher M., Vujic M., Weih F., Angel P., Herrlich P., Schutz G., EMBO J., 20, 7168-7173 (2001).

15) Reichardt H. M., Tuckermann J. P., Bauer A., Schutz G., $Z$. Rheumatol., 59, II/1-II/5 (2000).

16) Heck S., Kullmann M., Gast A., Ponta H., Rahmsdorf H. J., Herrlich P., Cato A. C., EMBO J., 13, 4087-4095 (1994).

17) Vayssiere B. M., Dupont S., Choquart A., Petit F., Garcia T., Marchandeau C., Gronemeyer H., Resche-Rigon M., Mol. Endocrinol., 11, 1245-1255 (1997).

18) Belvisi M. G., Wicks S. L., Battram C. H., Bottoms S. E., Redford J. E., Woodman P., Brown T. J., Webber S. E., Foster M. L., J. Immunol.,
166, 1975-1982 (2001).

19) Granner D. K., Tomkins G. M., Methods Enzymol., 17A, 633-637 (1970).

20) Tanigawa K., Tanaka K., Nagase H., Miyake H., Kiniwa M., Ikizawa K., Biol. Pharm. Bull., 25, 1115-1118 (2002).

21) Udvardi A., Kufferath I., Grutsch H., Zatloukal K., Volc-Platzer B., J. Mol. Med., 77, 744-750 (1999).

22) Lin M. T., Wang F., Uitto J., Yoon K., Br. J. Dermatol., 144, 34-39 (2001).

23) Belvisi M. G., Brown T. J., Wicks S., Foster M. L., Pulm. Pharmacol. Ther., 14, 221-227 (2001). 